\title{
131. Cytologic Studies of Tumors. LI
}

\author{
Notes on Some Abnormal Chromosome Features \\ in a Case of Mycosis Fungoides*) \\ By Yoshitaka OBARA,**) Sajiro Makino,**) \\ and Chikara MIKUNI***)
}

(Comm. by Yoshimaro TanakA, M. J. A., June 12, 1970)

A bulk of evidence has been gathered lately on cytogenetic features of various hematopoietic disorders such as leukemias, lymphomas, reticulosarcomas and others, providing data important for elucidation of the cytogenetic nature of malignant cells: differential response to therapeutic agents or cytogenetic evolution of malignant cells following therapeutic treatments, cytogenetic variability or invariability of malignant cells in different environments, and the mono- or polyclonal origin of malignant cell-lines (c.f. Spiers and Baikie 1968, Gartler et al. 1969, Obara et al. 1970b).

The present study deals with chromosome abnormalities and the occurrence of two cell lines with different proliferative ability in a case of mycosis fungoides. So far as we are aware, cytogenetic information has not been available for this disorder.

Materials and methods. Samples for chromosome studies were taken from the patient four times in peripheral blood, twice in bone marrow, and once each in skin tumor and lymph node during a period from November 28, 1969 to March 9, 1970.

One third of the samples from the above four tissues were directly prepared for chromosome slides following Tjio and Whang (1962), and the remaining samples were cultured according to Moorhead's method (1960) (see Obara et al. 1968). In lymph node, bone marrow and peripheral blood, two types of cultures were set up : one with the addition of phytohemagglutinin-M (PHA) at a final concentration of $0.02 \mathrm{ml} / \mathrm{ml}$ cell suspension and another without PHA. For skin cultures the plasma-clot technique was adopted.

Case history. Male, age 45. The patient had typhus at the age of 20 years, and received medical treatments for consumption for

*) Contributions from the Chromosome Research Unit, Faculty of Science, Hokkaido University, Sapporo, Japan. Supported by a grant from the Ministry of Education for Cancer Research (9001).

**) Chromosome Research Unit, Faculty of Science, Hokkaido University, Sapporo.

***) Internal Medicine, Sapporo National Hospital, Sapporo. 
eleven years. On October 29, 1969, he was hospitalized complaining of epiphora and severe pruritus. On hospitalization, the eruptions were remarkable on trunk, especially on abdominal region. A number of enlarged superficial lymph nodes, $10-20 \mathrm{~mm}$ in diameter, were recognized on both bilateral axillae and inguinal regions.

On October 31, 1969, he was diagnosed as mycosis fungoides through skin biopsy. From November 11, 1969, he received bleomycin therapy (15 $\mathrm{mg}$ twice/week, $150 \mathrm{mg}$ in total) in addition to SM and INA therapy for consumption. On and after December 16, 1969, he was treated with combined therapy with predonin $(30 \mathrm{mg}$ / day), endoxan ( $50 \mathrm{mg} /$ day) and vincristine ( $2 \mathrm{mg} /$ week) in lieu of bleomycin therapy. Then he relieved gradually, and the pruritic eruptions almost disappeared by March 9, 1970.

Hematologic data from peripheral blood were as follows (December 11, 1969) : RBC, $384 \times 10^{4}$; hemoglobin content, $12.6 \mathrm{~g} / \mathrm{dl}$; hematocrit, $34 \%$; platelet count, $22 \times 10^{4}$; WBC, 13,700 (small- and mediansized normal and atypical lymphocytes, $66 \%$; monocyte, $2.0 \%$; band form, $4.0 \%$; segmented polymorph, $24 \%$; eosinophil., $3.0 \%$; fasophil., 1.0\%). Atypical lymphocytes were characterized by the slightly to severely curved transformation of the nucleus without prominent nucleolus, and by several vacuoles in the cytoplasm. They were not clearly distinguished from normal lymphocytes, because there were intermediate types between normal and atypical lymphocytes. Probably they may be lymphoreticular cells migrated from tumors of mycosis fungoides.

Cytologic findings and remarks. Two karyologically abnormal
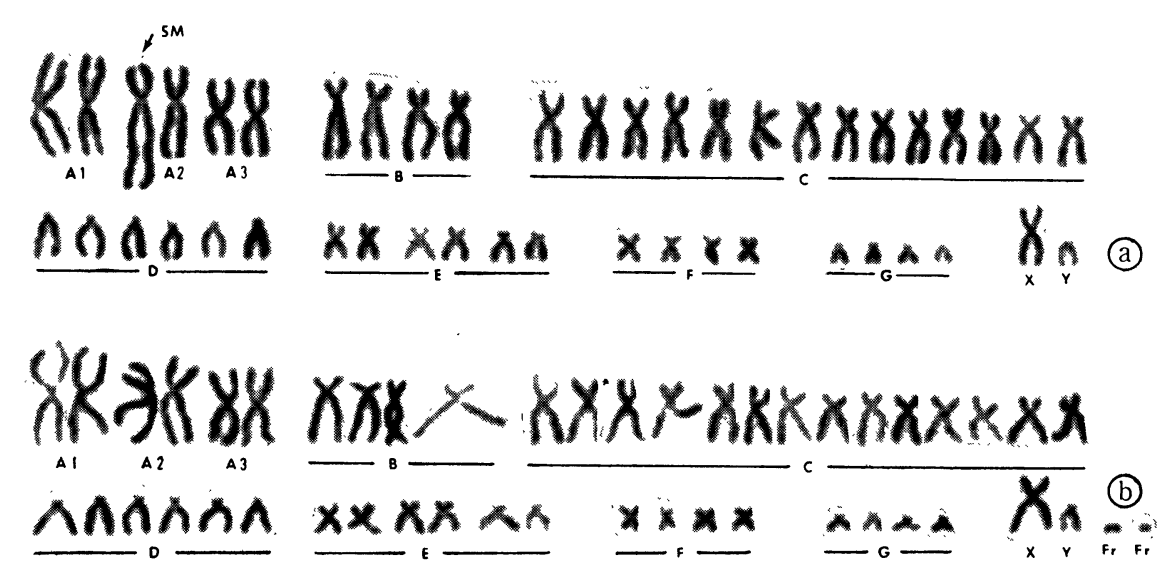

Fig. 1. a: Karyotype characterized by an SM marker (arrow) directly prepared from lymph node. Note the loss of one $A_{2}$ chromosome. b: Karyotype characterized by two extra minute fragments directly prepared from peripheral blood. 
cell lines were noted in samples from skin tumor, enlarged lymph node, bone marrow and peripheral blood. The one was predominant and characterized by the $46, \mathrm{XY}$ chromosome constitution having a large submetacentric marker $(\mathrm{SM})$ in lieu of one $\mathrm{A}_{2}$ chromosome, and the other by the 48, XY constitution with two extra minute fragments (Fig. 1a and b). The SMI marker was tentatively interpreted as being originated from one $\mathrm{A}_{2}$ chromosome, probably through a reciprocal translocation between long arms of one $\mathrm{A}_{2}$ chromosome and a part of some unknown element. The origin of two fragments remains unknown. A few cells with the $47, \mathrm{XY}$ constitution having only one minute fragment occurred in addition to the above 48chromosome line. As shown in Tables I and II, metaphases with the marker or fragments were in general more frequent in direct samples than in cultured cells, when examined at the rapid proliferation phase. The frequencies of cells with those abnormal chromosomes were as follows: $84.1 \%$ for lymph node, $69.8 \%$ for peripheral blood, $8.0 \%$

Table I. Cytogenetic features in cells from cultured and directly prepared peripheral blood

\begin{tabular}{|c|c|c|c|c|c|c|c|c|c|c|}
\hline \multirow{2}{*}{$\begin{array}{l}\text { Date of } \\
\text { sampling }\end{array}$} & \multirow{2}{*}{$\begin{array}{c}\text { Days } \\
\text { in vitro }\end{array}$} & \multirow[b]{2}{*}{ PHA } & \multicolumn{6}{|c|}{ No. of cells with } & \multirow[b]{2}{*}{ others } & \multirow{2}{*}{$\begin{array}{c}\text { Total } \\
\text { no. of } \\
\text { cells } \\
\text { obsvd. }\end{array}$} \\
\hline & & & SM & $1 \mathrm{Fr}$. & 2Frs. & $\begin{array}{c}\text { N. } \\
\text { chroms. }\end{array}$ & tetra & S.R & & \\
\hline \multirow{3}{*}{ Nov. 28 , '69 } & (direct) & - & 29 & & 1 & 15 & & & & 45 \\
\hline & \multirow[b]{2}{*}{3} & + & & & & 74 & $1^{\dagger}$ & 3 & & 78 \\
\hline & & - & & & & 2 & & & & 2 \\
\hline \multirow{5}{*}{ Dec. 8, '69 } & (direct) & - & 31 & 3 & 3 & 12 & 1 & 1 & & 51 \\
\hline & \multirow{2}{*}{2} & + & 1 & & & 47 & $1^{*}$ & 1 & & 50 \\
\hline & & - & 2 & 1 & 1 & 4 & & & & 8 \\
\hline & \multirow{2}{*}{3} & + & & 1 & & 46 & & 3 & & 50 \\
\hline & & - & 3 & & & 10 & 1 & 1 & & 15 \\
\hline \multirow{3}{*}{ Dec. 23, '69 } & (direct) & - & & & & 5 & & & & 5 \\
\hline & \multirow{2}{*}{4} & + & & & & 50 & 5 & 5 & & 60 \\
\hline & & - & 1 & & & 16 & $4^{* *}$ & 1 & & 22 \\
\hline \multirow{3}{*}{$\operatorname{March} 9,{ }^{\prime} 70$} & (direct) & - & & & & 35 & & & & 35 \\
\hline & \multirow[t]{2}{*}{3} & + & & & & 44 & $2^{\dagger}$ & 1 & $3 * * *$ & 50 \\
\hline & & - & & & & 6 & & & & 6 \\
\hline
\end{tabular}

SM: large submetacentric marker, Fr.: minute fragment, N. chroms.: normal chromosomes (modal number, 46), S. R: Severely rearranged chromosome constitution involving tetra-, tri-, dicentrics, acentrics, fragments, rings, and other abnormalities. *: a cell with one SM marker. **: including a cell with one SM marker and three $\mathrm{A}_{3}$ and a cell with one fragment. $* * *: 45, \mathrm{XY}, \mathrm{B}_{q+}, \mathrm{C}-, 46, \mathrm{XY}, \mathrm{G}_{q-}$, and $47, \mathrm{XY}, \mathrm{B}_{p-}, ? \mathrm{G}+$. $t$ : an endoreduplicated cell, each. 


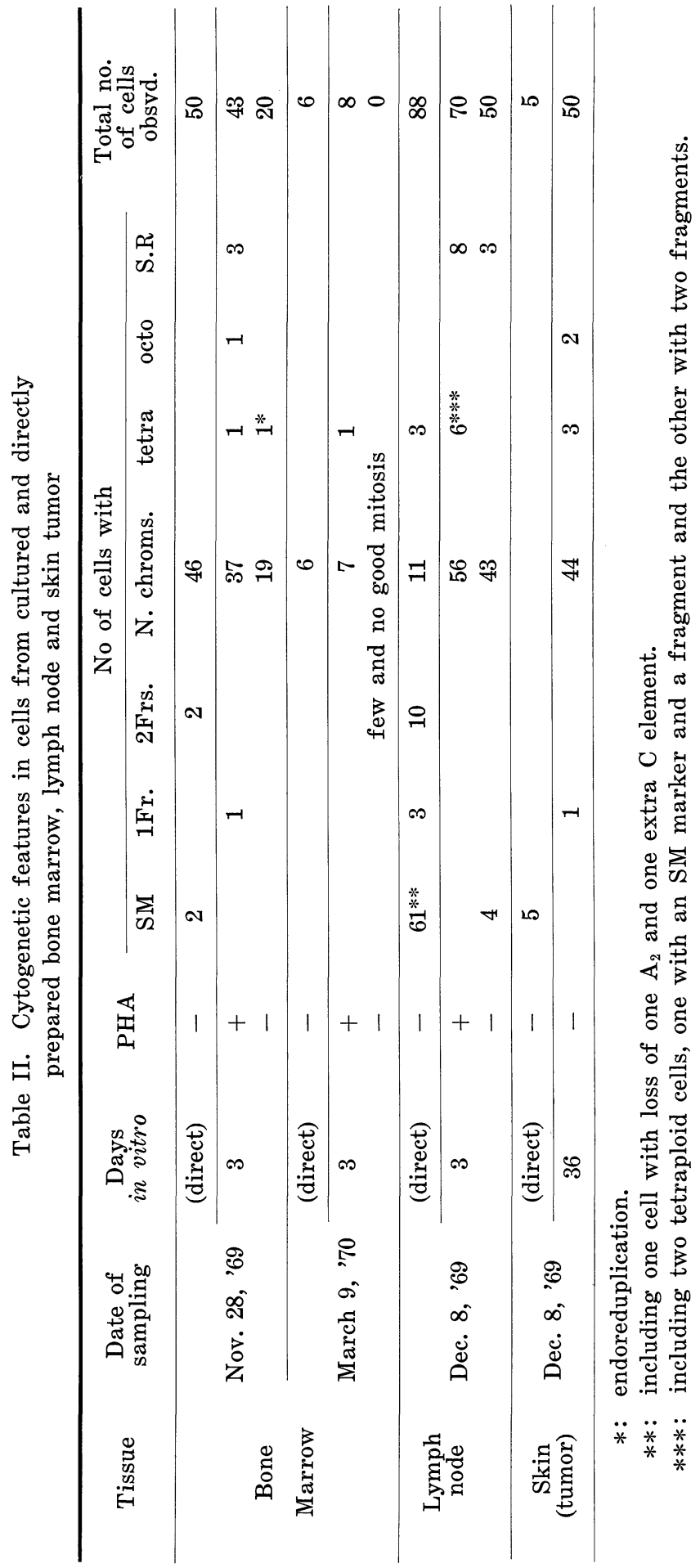


for bone marrow and $100.0 \%$ for skin tumor. The situation was quite different in cultured samples. The frequencies of cells with SM marker or fragments were $2.9 \%$ and $8.0 \%$ in PHA-treated and non-PHA lymph node cultures, $1.1 \%$ and $24.0 \%$ in PHA-treated and non-treated blood cultures, $2.0 \%$ in skin tumor cultured for 36 days, and $0.0 \%$ in PHA-treated and non-treated marrow cultures (Tables I and II). In short, the two cell lines proliferate predominantly in the in vivo environment of blood and lymph node, while they show an apparently low proliferative ability in both non-PHA and PHAtreated cultures. The above data strongly point to the possibility that these two cell lines are those of malignant cells in this disorder.

In malignant hematopoietic disorders such as leukemias, lymphomas and reticulosarcomas, non-PHA cultures of peripheral blood, marrow and lymph node are usually rather reliable for examination of the chromosomes, since their malignant cells have higher potentiality of proliferation in the culture environment (Sandberg et al. 1964, Makino et al. 1969, Obara et al. 1970a, b). The malignant cell lines of mycosis fungoides here dealt with appeared, however, less suitable for the in vitro condition. Mycosis fungoides is clinically considered as a less malignant disease with longer expectancy in comparison with leukemias and lymphomas. The inactivity of malignant cells in cultures observed in this case is of interest in relation to malignancy.

There were cells having an apparently normal chromosome constitution in non-PHA blood cultures with a low frequency. On the basis of the fact that non-PHA blood cultures of normal human subjects show an extremely low mitotic frequency at least for the first three days, the chromosomally normal cells occurring in the present case may not always be of non-malignant nature.

Thirty tetraploid cells occurred in a total of 876 metaphases observed in the four tissues. Two of them had one SM marker, and one carried one SM and one fragment, while the remaining 27 cells showed no such ones. The union of abnormal and normal diploid cells is considered for the formation of the abnormal tetraploid cells, though there is no direct proof. A chromosomal translocation leading to the formation of the SM marker may also be conceivable following tetraploidization of normal diploid cells. There were also $30 \mathrm{ab}-$ normal cells containing tetra-, tri-, di- and acentrics, fragments, rings, and others, and showing near-diploid to near-tetraploid numbers (Tables I and II). They occurred frequently in PHA-treated peripheral blod, lymph node and bone marrow cultures, and less frequently in directly prepared blood samples and non-PHA cultures of peripheral blood and lymph node. Such chromosome abnormalities were 
found to occur in several other bleomycin-treated hematopoietic disorders, as well as in bleomycin-treated normal human blood cultures. Most probably, their occurrence is associated with bleomycin therapy. Further statements on this respect may be made in near future, since cytogenetic effects of bleomycin on normal human lymphocytes have been studying in detail by the senior author.

Summary. Some cytogenetic features of mycosis fungoides are described. Two chromosomally abnormal malignant cell lines are noted in each sample from skin tumor, enlarged lymph node, bone marrow and peripheral blood of the patient: the one is characterized by a large submetacentric marker (SM), and the other by two minute fragments. These two lines proliferate predominantly in the in vivo environment of blood and lymph node, while they show an extremely low proliferative ability in non-PHA and PHA-treated cultures.

Acknowledgement. We are much obliged to Professor Motomichi Sasaki for his invaluable suggestion and important criticism. Thanks are also due to Dr. T. Sasaki for clinical advice.

\section{References}

Gartler, S. M., Ziprkowski, L., Krakowski, R. E., Szeinberg, A., and Adams, A. (1966): Amer. J. Human Genet., 18, 282-287.

Makino, S., Obara, Y., Sasaki, M., Ohshima, M., and Mikuni, C. (1969): Cancer, 24, 758-763.

Moorhead, P. S., Nowell, P. C., Mellman, W. J., Battips, D. M., and Hungerford, D. A. (1960): Exptl. Cell Res., 20, 613-616.

Obara, Y., Makino, S., Ohshima, M., and Mikuni, C. (1968): Jour. Fac. Sci. Hokkaido Univ. Ser. VI, Zool., 16, 632-639.

Obara, Y., Makino, S., and Mikuni, C. (1970a): GANN, 61, 1-6.

Obara, Y., Sasaki, M., Makino, S., and Mikuni, C. (1970b): Submitted to Blood. Sandberg, A. A., Kikuchi, Y., and Crosswhite, L. H. (1964): Cancer Res., 24, 1468-1473.

Spiers, A. S. D., and Baikie, A. G. (1968): Brit. J. Cancer, 22, 192-204.

Tjio, J. H., and Whang, J. (1962): Stain Techn., 37, 17-20. 